\title{
Comparative Evaluation of Sighted and Visually Impaired Subjects using a Mobile Application for Reducing Veering during Blindfolded Walking
}

\author{
H. Nagy, Gy. Wersényi \\ Széchenyi István University, Department of Telecommunications \\ Egyetem tér 1, H-9026, Győr, Hungray \\ E-mail:wersenyi@sze.hu; nhunorz@gmail.com
}

\begin{abstract}
Measurements were conducted using a navigational application on an Android Smartphone that provides auditory and haptic feedback based on electromagnetic sensor data (compass) in order to help users walk in a straight line. Blindfolded sighted subjects attempted to walk along a 40meter path with and without navigational assistance. Results showed that optimal settings of accuracy, sensitivity and target direction on the device can significantly reduce veering. Further, it was shown that even a short training session consisting of four trials could lead to better subsequent performance without navigational assistance.
\end{abstract}

Keywords: mobile device, veering, blind user, acoustic feedback

\section{Introduction}

Assistive technology affects development in both the engineering sciences and informatics. Target groups include people with sensory disabilities, such as visual impairment, hearing loss or movement disorders. State-of-the-art technologies offer portable devices characterized by light weight, long endurance, increased computational power with built-in sensors and applications with user friendly interfaces, easy accessibility. Often, such devices also provide openly extensible platforms for developers.

The most important human sensory system is vision. About $90 \%$ of information about our surroundings is gathered through this modality. At the same time, more than 285 million people were affected by visual impairment in 2012 [1]. Loss of vision affects all areas of everyday life, including activities such as (safe) navigation and entertainment. Assistive devices have been developed and introduced to the blind community for many years, focusing on different problems such as reading (text-to-speech applications), 
navigation (Electronic Travel Aids [2-5]), and user interfaces for movement in computer environments and through menu structures [6-9], etc.

The common assumption underlying all such developments has been that sensory substitution is possible through neuroplasticity $[1,10]$. The brain can build and establish new connections by "rewiring" itself, thereby enhancing and increasing the accuracy and sensitivity of other sensory organs. Auditory and haptic channels can be used to replace degraded or lost vision. Sound events, including speech, music and other representation formats are naturally adopted by users, although parameters such as quality, spatial resolution, number of concurrent sources etc. need to be calibrated and adjusted.

The most important task for blind people is navigation. Information about the surroundings is essential for a safe and independent life. Information dimensions such as "what", "where" and "how to get there" are of key importance. Mobile devices (smartphones, mini PCs) are equipped with sensors, sound rendering tools, feedback devices and enough computational power to serve as a basis for application development. Based on long-term cooperation with the blind community, a wide range of needs and problems were explored [11-15]. For example, one navigational task that is essential to the visually impaired is the ability to walk in straight line and avoid veering. Clearly this touches on safety issues that can be examined and if needed, assisted by a device and/or application.

During training of the blind, several tasks and navigational training scenarios are implemented. These focus on basic navigational strategies and on the most common problems. E.g. echolocation, avoiding obstacles, orientation and mobility issues, Braille reading. One of the tasks they train is to learn how to walk straight in unfamiliar places without any other cue. This may happen in floors, larger (empty) rooms, or outdoor environments such as long, wide streets, squares, meadows. Not only safety (walking off the pavement) but also orientation can suffer from serious veering. Furthermore, less veering results in faster and safer walking.

This paper presents results in connection with a veering avoidance application developed on the Android platform for smartphones. The application was tested in reallife environments with blind and blindfolded sighted users to assist walking in a straight line using the built-in magnetic sensor and auditory feedback. We first give an overview of earlier results and developments on electronic travel aids and applications. Then, the application and the measurement environment will be presented, followed by a presentation of the results obtained during outdoor walks using the system. Finally, a discussion of the results and further directions of developments will be highlighted.

\subsection{Former Results}

People walking on unfamiliar terrain with no external reference (i.e., no focal points such as mountains, buildings, or the sun) usually walk in circles or veer from the straight direct path. Non-scientific tests can be viewed on different sites including Youtube [16-18], but more scientific approaches have also been employed to explore and provide an explanation of this phenomenon. Underlying reasons can include differences in leg length, brain dominance, left or right-handedness and footedness, 
territorial instinct, mathematical probabilities etc., but none of these factors explain veering in decisive terms, and any one of them can be argued against as a crucial factor [19-23]. Nevertheless, biomedical asymmetries definitely play a role in veering [21, 2429]. Scientific experiments were carried out in deserts and forests [30], or using previously seen targets [28-35]. Most of these experiments show an overlapping of scientific fields such as engineering, informatics, medicine or experimental psychology. Furthermore, the usual number of subjects is very low (1-4), thus, statistical relevance is questionable.

All of this led us to set up an experiment involving blindfolded sighted and also blind subjects in order to test veering effects with and without auditory beacon signals [11]. The goal was to test both groups and two different sound stimuli. In the first reported experiment, 120 sighted subjects were asked to follow a 40-meter straight line first without any auditory beacon, and second using two sound signals (white noise and click-train) radiated by a loudspeaker. The evaluation was based on GPS-tracked log files. Figure 1 shows results of the sighted subjects with and without acoustic stimuli.
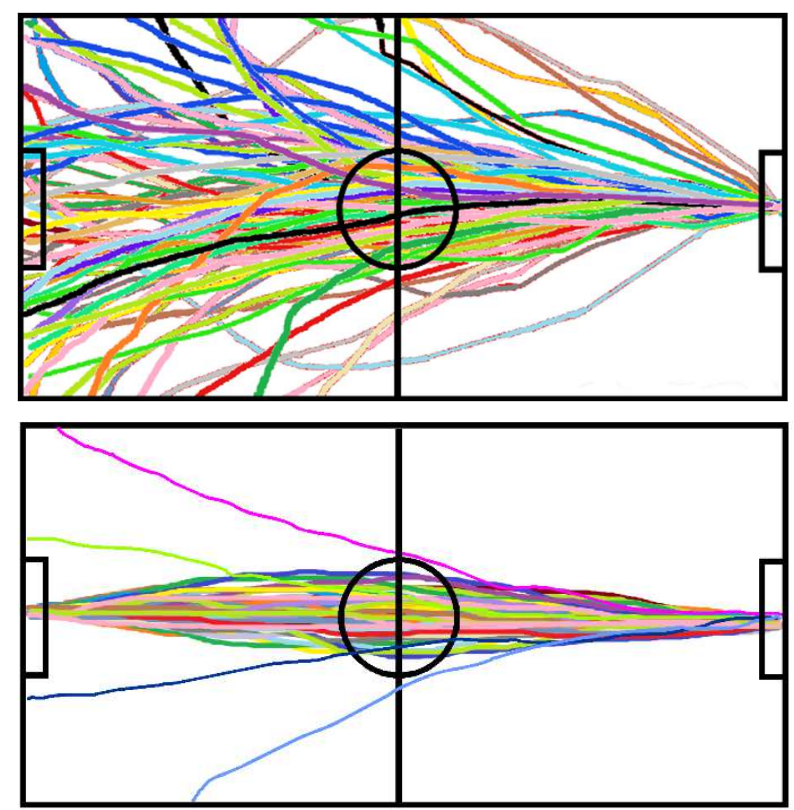


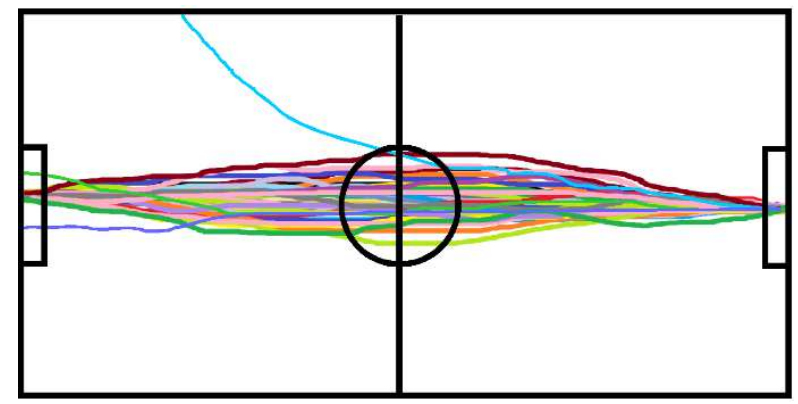

Figure 1. Walking trajectories from right to left for 120 blindfolded sighted subjects based on GPS tracking during the first try without sound (top), using click-train signal as reference (middle) and using white noise (bottom) [11].

\section{Measurement setup}

In order to help blind people to walk in a straight line, an application was developed to assist in avoiding veering and increase safety during every-day walking [36]. The main characteristics of the development were:

- use of an open-source platform (Android),

- creation of easy accessibility for both developers (sighted mode) and blind users (navigation mode),

- use of one or more built-in sensors of a smartphone (magnetic sensor, accelerometer, gyro sensor),

- functionality in indoor and outdoor environments (no GPS usage or preinstalled systems such as RFID sensor or similar),

- feedback with sounds, including speech and different beeps with option of vibration,

- $\quad$ settings for user preferences for feedback, accuracy, sensitivity etc.

During development, the main focus of testing was directed toward the sensors and default parameter settings. The only sensor accurate, sensitive and responsive enough for this purpose was the magnetic sensor, basically functioning as a compass.

During operation, the user sets the desired direction by holding the device in front of his or her body. As a result, the extent of veering (in degrees) to the left or right can be monitored during movement. The navigation can be started and stopped by swiping the screen (Figure 2.). If the value exceeds a pre-defined value, the subject is instructed to head left or right, as necessary. To avoid small deviations in the detected direction, a filter is applied that averages measured data over the last 5 seconds. The sensor rate can be set in microseconds, corresponding to a sample rate for collecting data. The optimal rate was set as default $0,27 \mathrm{~s}$ for updating the direction and 7 degrees for deviation limit (Figure 3). These default values were determined based on a pre-test with the subjects. 


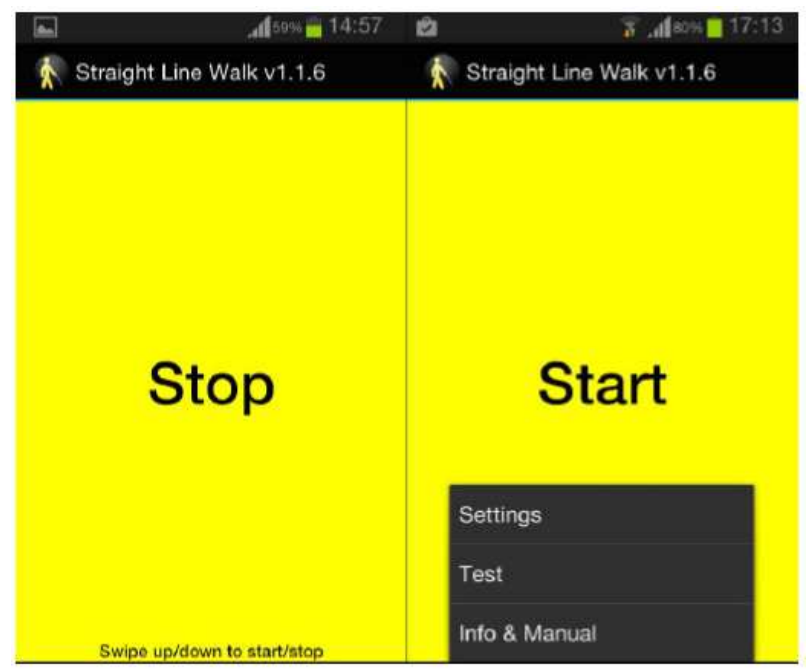

Figure 2. Screenshot of the user interface. Swiping the screen up and down will activate or stop the navigation respectively. For sighted developers, a settings menu and a special test mode can be activated. The "Info \& Manual" section is a written text that can be read by the system (text-to-speech).
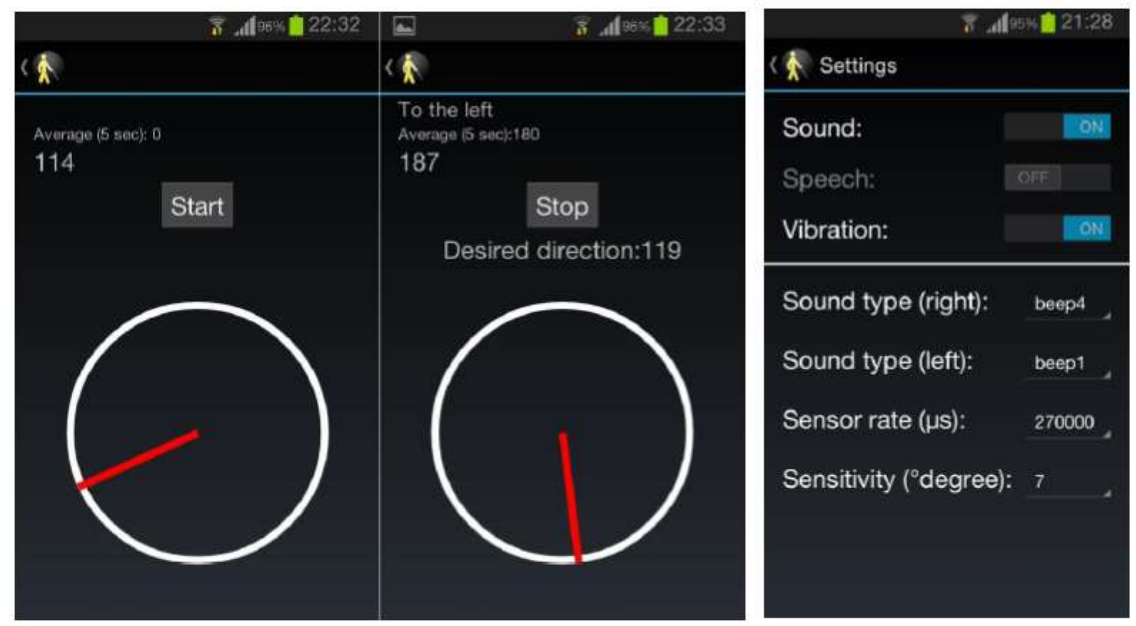

Figure 3. Screenshot of the user interface during navigation (left) and settings mode (right). If the actual direction differs more than 7 degrees from the "desired direction" after a time average of 5 seconds, the user will be instructed to update his or her direction to the left or right.

During walking, subjects held the device in their hand, setting the direction along the handball court used in the preliminary experiments (Figure 4.). First they walked 
without the application active, followed by an activated session. Following this, the test was repeated. Figure 5 shows the directions and the numbering of the runs (1-8). A 40meter long track was selected for walking, and if subjects walked off the path 0.75 meters to the left or right, the experiment was stopped. Time and destination from the start was measured for statistical analysis.

Later, a second test series was conducted with the same conditions but instead of holding the device, it was applied on a belt around the hip to avoid unwanted unsynchronized movements of the body.

The first experiment had 14 subjects ( 8 males, 6 females), while the second one was conducted with the participation of 18 subjects (10 males, 8 females). In the previous experiment, other parameters of the human hearing system were also investigated (blind persons, left and right handedness, different acoustic beacon signals etc.) that required more subjects for a correct evaluation. Here, only a smaller number of participants were recruited to test a mobile application targeted to reduce veering.
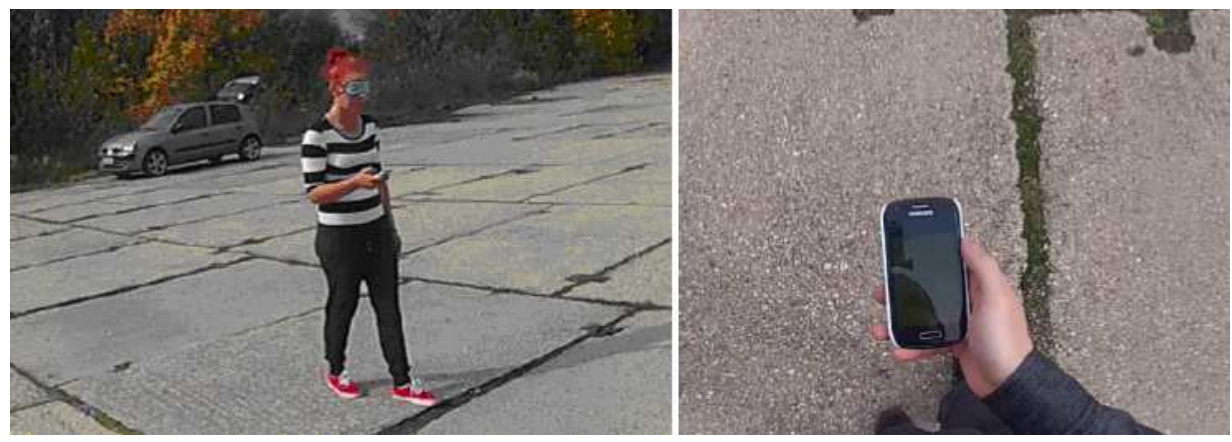

Figure 4. A blindfolded subject during testing (left) and the proper way to hold the device during navigation (right).

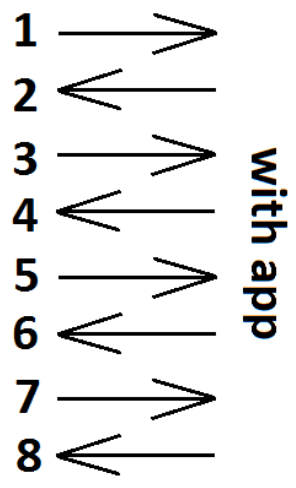

Figure 5. Every subject performed 8 runs. The first two and the last two were performed without the application active. Runs 3-6 were performed with the app active. 
In the first setup, the device was held in the hand (as on Fig.4.), whilst in the second setup it was applied on a belt around the hip.

\section{Results}

Results of the ANOVA test of the first experimental setup, with the device in the hand, are shown on figures 6-7 and in table 1. The same is shown in figures 8-9 and table 2 for the second experiment.

Results were recorded in unsigned absolute values measured from the start until the point the subject veered from the straight line more than 0.75 meters left or right. Mean and SD values in figures 6 and 8 were calculated based on run 1 and run 2. Similarly, mean and SD values were calculated for runs 7 and 8 . These were performed after having four runs with the application active (training). Figures 7 and 9, and tables 1-2 show the corresponding boxplots and ANOVA results.

\begin{tabular}{|c|r|r|c|c|c|}
\hline Member & \multicolumn{1}{|c|}{ Mean } & \multicolumn{1}{c|}{ SD } & Member & Mean & SD \\
\hline 1 & $745,00 \mathrm{~cm}$ & $103,24 \mathrm{~cm}$ & 1 & $2868,50 \mathrm{~cm}$ & $2336,00 \mathrm{~cm}$ \\
\hline 2 & $739,50 \mathrm{~cm}$ & $183,14 \mathrm{~cm}$ & 2 & $2029,50 \mathrm{~cm}$ & $1603,00 \mathrm{~cm}$ \\
\hline 3 & $625,50 \mathrm{~cm}$ & $58,69 \mathrm{~cm}$ & 3 & $1374,50 \mathrm{~cm}$ & $1283,50 \mathrm{~cm}$ \\
\hline 4 & $913,00 \mathrm{~cm}$ & $346,48 \mathrm{~cm}$ & 4 & $2950,00 \mathrm{~cm}$ & $2334,00 \mathrm{~cm}$ \\
\hline 5 & $799,00 \mathrm{~cm}$ & $159,81 \mathrm{~cm}$ & 5 & $2489,00 \mathrm{~cm}$ & $2243,00 \mathrm{~cm}$ \\
\hline 6 & $835,50 \mathrm{~cm}$ & $317,49 \mathrm{~cm}$ & 6 & $2358,00 \mathrm{~cm}$ & $1530,50 \mathrm{~cm}$ \\
\hline 7 & $1234,00 \mathrm{~cm}$ & $305,47 \mathrm{~cm}$ & 7 & $2548,50 \mathrm{~cm}$ & $1832,50 \mathrm{~cm}$ \\
\hline 8 & $937,50 \mathrm{~cm}$ & $655,49 \mathrm{~cm}$ & 8 & $2213,00 \mathrm{~cm}$ & $1376,50 \mathrm{~cm}$ \\
\hline 9 & $538,00 \mathrm{~cm}$ & $299,81 \mathrm{~cm}$ & 9 & $2244,50 \mathrm{~cm}$ & $1567,50 \mathrm{~cm}$ \\
\hline 10 & $2346,50 \mathrm{~cm}$ & $71,42 \mathrm{~cm}$ & 10 & $3394,00 \mathrm{~cm}$ & $3148,00 \mathrm{~cm}$ \\
\hline 11 & $437,50 \mathrm{~cm}$ & $17,68 \mathrm{~cm}$ & 11 & $1037,00 \mathrm{~cm}$ & $745,50 \mathrm{~cm}$ \\
\hline 12 & $958,00 \mathrm{~cm}$ & $479,42 \mathrm{~cm}$ & 12 & $1717,50 \mathrm{~cm}$ & $1243,50 \mathrm{~cm}$ \\
\hline 13 & $979,50 \mathrm{~cm}$ & $195,87 \mathrm{~cm}$ & 13 & $1610,50 \mathrm{~cm}$ & $1293,50 \mathrm{~cm}$ \\
\hline 14 & $270,00 \mathrm{~cm}$ & $63,64 \mathrm{~cm}$ & 14 & $732,50 \mathrm{~cm}$ & $587,50 \mathrm{~cm}$ \\
\hline
\end{tabular}

Figure 6. Results of the 14 participants in the first experiment at the beginning (runs 1-2 on the left) and at the end (runs 7-8 on the right). 


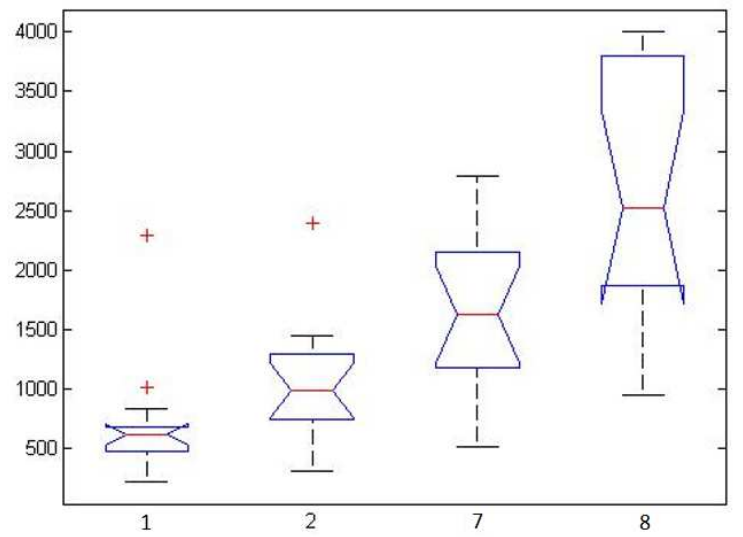

Figure 7. Boxplots of the ANOVA analysis of the results in runs 1-2 and 7-8 based on table 1 .

Table 1. ANOVA results based on figure 6.

\begin{tabular}{llllll}
\hline \hline Source & SS & df & MS & F & Prob $>$ F \\
\hline Columns & $2,82 \mathrm{E}+07$ & 3 & 9394737 & 18,6 & $2,46 \mathrm{E}-08$ \\
\hline Error & $2,62 \mathrm{E}+07$ & 52 & 504402,5 & & \\
\hline Total & $5,44 \mathrm{E}+07$ & 55 & & &
\end{tabular}




\begin{tabular}{|c|r|r||r|r|r|}
\hline Member & \multicolumn{1}{|c|}{ Mean } & \multicolumn{1}{c|}{ SD } & Member & Mean & \multicolumn{1}{c|}{ SD } \\
\hline 15 & $1790,00 \mathrm{~cm}$ & $523,26 \mathrm{~cm}$ & 15 & $3803,50 \mathrm{~cm}$ & $277,89 \mathrm{~cm}$ \\
\hline 16 & $1375,50 \mathrm{~cm}$ & $48,79 \mathrm{~cm}$ & 16 & $2676,00 \mathrm{~cm}$ & $333,75 \mathrm{~cm}$ \\
\hline 17 & $1602,00 \mathrm{~cm}$ & $469,52 \mathrm{~cm}$ & 17 & $2658,00 \mathrm{~cm}$ & $766,50 \mathrm{~cm}$ \\
\hline 18 & $2133,50 \mathrm{~cm}$ & $47,38 \mathrm{~cm}$ & 18 & $2637,50 \mathrm{~cm}$ & $519,72 \mathrm{~cm}$ \\
\hline 19 & $828,00 \mathrm{~cm}$ & $55,15 \mathrm{~cm}$ & 19 & $2556,00 \mathrm{~cm}$ & $910,75 \mathrm{~cm}$ \\
\hline 20 & $1495,00 \mathrm{~cm}$ & $799,03 \mathrm{~cm}$ & 20 & $3040,00 \mathrm{~cm}$ & $585,48 \mathrm{~cm}$ \\
\hline 21 & $1234,00 \mathrm{~cm}$ & $305,47 \mathrm{~cm}$ & 21 & $2548,50 \mathrm{~cm}$ & $139,30 \mathrm{~cm}$ \\
\hline 22 & $2461,50 \mathrm{~cm}$ & $1768,47 \mathrm{~cm}$ & 22 & $3450,00 \mathrm{~cm}$ & $777,82 \mathrm{~cm}$ \\
\hline 23 & $1094,00 \mathrm{~cm}$ & $434,16 \mathrm{~cm}$ & 23 & $2213,00 \mathrm{~cm}$ & $93,34 \mathrm{~cm}$ \\
\hline 24 & $909,50 \mathrm{~cm}$ & $102,53 \mathrm{~cm}$ & 24 & $2244,50 \mathrm{~cm}$ & $798,32 \mathrm{~cm}$ \\
\hline 25 & $1808,50 \mathrm{~cm}$ & $832,26 \mathrm{~cm}$ & 25 & $3394,00 \mathrm{~cm}$ & $857,01 \mathrm{~cm}$ \\
\hline 26 & $702,50 \mathrm{~cm}$ & $109,60 \mathrm{~cm}$ & 26 & $1037,00 \mathrm{~cm}$ & $41,01 \mathrm{~cm}$ \\
\hline 27 & $958,00 \mathrm{~cm}$ & $466,69 \mathrm{~cm}$ & 27 & $1717,50 \mathrm{~cm}$ & $212,84 \mathrm{~cm}$ \\
\hline 28 & $979,50 \mathrm{~cm}$ & $195,87 \mathrm{~cm}$ & 28 & $1935,50 \mathrm{~cm}$ & $71,42 \mathrm{~cm}$ \\
\hline 29 & $844,50 \mathrm{~cm}$ & $164,76 \mathrm{~cm}$ & 29 & $2441,00 \mathrm{~cm}$ & $1090,36 \mathrm{~cm}$ \\
\hline 30 & $1717,00 \mathrm{~cm}$ & $569,93 \mathrm{~cm}$ & 30 & $3086,50 \mathrm{~cm}$ & $318,91 \mathrm{~cm}$ \\
\hline 31 & $756,50 \mathrm{~cm}$ & $163,34 \mathrm{~cm}$ & 31 & $1778,50 \mathrm{~cm}$ & $613,06 \mathrm{~cm}$ \\
\hline 32 & $690,50 \mathrm{~cm}$ & $318,91 \mathrm{~cm}$ & 32 & $2427,50 \mathrm{~cm}$ & $915,70 \mathrm{~cm}$ \\
\hline
\end{tabular}

Figure 8. Results of the 18 participants in the second experiment at the beginning (runs 1-2 on the left) and at the end (runs 7-8 on the right).

Table 2. ANOVA results based on figure 8 .

\begin{tabular}{llllll}
\hline \hline Source & SS & df & MS & F & Prob $>$ F \\
\hline Columns & $3,54 \mathrm{E}+07$ & 3 & 11796713,4 & 26,68 & $1,61 \mathrm{E}-11$ \\
\hline Error & $3,01 \mathrm{E}+07$ & 68 & 442113,9 & & \\
\hline Total & $6,55 \mathrm{E}+07$ & 71 & & &
\end{tabular}




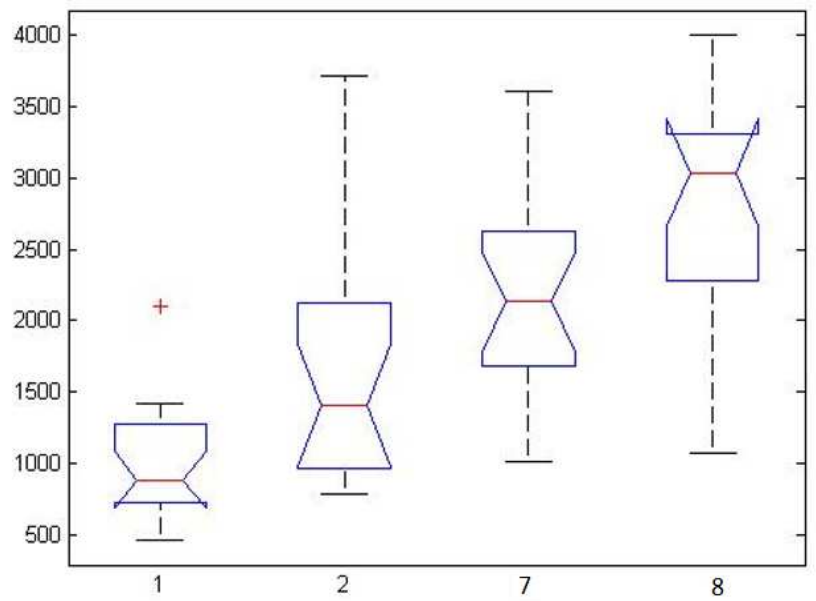

Figure 9. Boxplots of the ANOVA analysis of the results in runs 1-2 and 7-8 based on table 2.

Figure 10 shows results using the application based on runs 3-6.

\begin{tabular}{|c|c|c|c|c|c|c|c|}
\hline & & & & Member & IViean & עת & Median \\
\hline & & & & 15 & $1599,75 \mathrm{~cm}$ & $464,63 \mathrm{~cm}$ & $1509,50 \mathrm{~cm}$ \\
\hline & & & & 16 & $3396,75 \mathrm{~cm}$ & $862,78 \mathrm{~cm}$ & $3708,50 \mathrm{~cm}$ \\
\hline & & & & 17 & $3179,50 \mathrm{~cm}$ & $929,01 \mathrm{~cm}$ & $3266,00 \mathrm{~cm}$ \\
\hline Member & Mean & SD & Median & 18 & $2857,50 \mathrm{~cm}$ & $922,26 \mathrm{~cm}$ & $2837,00 \mathrm{~cm}$ \\
\hline 1 & $3215,00 \mathrm{~cm}$ & $1471,70 \mathrm{~cm}$ & $3925,00 \mathrm{~cm}$ & 19 & $1946,50 \mathrm{~cm}$ & $1468,93 \mathrm{~cm}$ & $1511,50 \mathrm{~cm}$ \\
\hline 2 & $3417,00 \mathrm{~cm}$ & $551,86 \mathrm{~cm}$ & $3427,00 \mathrm{~cm}$ & 20 & $1815,50 \mathrm{~cm}$ & $804,10 \mathrm{~cm}$ & $1706,00 \mathrm{~cm}$ \\
\hline 3 & $3492,00 \mathrm{~cm}$ & $925,02 \mathrm{~cm}$ & $3930,00 \mathrm{~cm}$ & 21 & $1162,25 \mathrm{~cm}$ & $389,20 \mathrm{~cm}$ & $1180,50 \mathrm{~cm}$ \\
\hline 4 & $3967,75 \mathrm{~cm}$ & $64,50 \mathrm{~cm}$ & $4000,00 \mathrm{~cm}$ & 22 & $2997,75 \mathrm{~cm}$ & $906,50 \mathrm{~cm}$ & $2883,50 \mathrm{~cm}$ \\
\hline 5 & $3099,75 \mathrm{~cm}$ & $1337,37 \mathrm{~cm}$ & $3615,00 \mathrm{~cm}$ & 23 & $3299,75 \mathrm{~cm}$ & $802,09 \mathrm{~cm}$ & $3515,00 \mathrm{~cm}$ \\
\hline 6 & $3093,50 \mathrm{~cm}$ & $1031,51 \mathrm{~cm}$ & $3317,50 \mathrm{~cm}$ & 24 & $1885,00 \mathrm{~cm}$ & $749,30 \mathrm{~cm}$ & $1978,50 \mathrm{~cm}$ \\
\hline 7 & $2355,75 \mathrm{~cm}$ & $1172,81 \mathrm{~cm}$ & $2091,50 \mathrm{~cm}$ & 25 & $2355,75 \mathrm{~cm}$ & $1172,81 \mathrm{~cm}$ & $2091,50 \mathrm{~cm}$ \\
\hline 8 & $2346,25 \mathrm{~cm}$ & $1138,36 \mathrm{~cm}$ & $2281,50 \mathrm{~cm}$ & 26 & $2964,00 \mathrm{~cm}$ & $617,18 \mathrm{~cm}$ & $2965,00 \mathrm{~cm}$ \\
\hline 9 & $3188,00 \mathrm{~cm}$ & $815,63 \mathrm{~cm}$ & $3266,00 \mathrm{~cm}$ & 27 & $3045,50 \mathrm{~cm}$ & $1266,45 \mathrm{~cm}$ & $3427,50 \mathrm{~cm}$ \\
\hline 10 & $3045,50 \mathrm{~cm}$ & $1266,45 \mathrm{~cm}$ & $3427,50 \mathrm{~cm}$ & 28 & $2715,75 \mathrm{~cm}$ & $1484,38 \mathrm{~cm}$ & $2756,00 \mathrm{~cm}$ \\
\hline 11 & $2715,75 \mathrm{~cm}$ & $1484,38 \mathrm{~cm}$ & $2756,00 \mathrm{~cm}$ & 29 & $3116,50 \mathrm{~cm}$ & $1105,32 \mathrm{~cm}$ & $3377,00 \mathrm{~cm}$ \\
\hline 12 & $3116,50 \mathrm{~cm}$ & $1105,32 \mathrm{~cm}$ & $3377,00 \mathrm{~cm}$ & 30 & $2366,50 \mathrm{~cm}$ & $861,24 \mathrm{~cm}$ & $2454,50 \mathrm{~cm}$ \\
\hline 13 & $2416,50 \mathrm{~cm}$ & $775,24 \mathrm{~cm}$ & $2454,50 \mathrm{~cm}$ & 31 & $3323,75 \mathrm{~cm}$ & $783,23 \mathrm{~cm}$ & $3361,00 \mathrm{~cm}$ \\
\hline 14 & $3323,75 \mathrm{~cm}$ & $783,23 \mathrm{~cm}$ & $3361,00 \mathrm{~cm}$ & 32 & $3054,75 \mathrm{~cm}$ & $1130,47 \mathrm{~cm}$ & $3367,50 \mathrm{~cm}$ \\
\hline
\end{tabular}

Figure 10. Results of four test runs (3-6) with activated application in the first experiment (left) and the second experiment (right). 


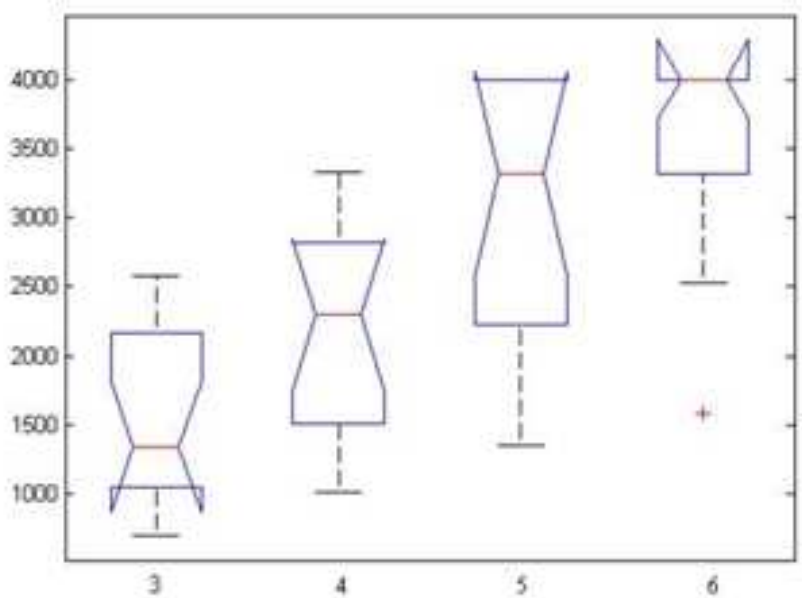

Figure 11. Boxplot of ANOVA based on figure 10 and table 3 (first experiment, 14 participants)

Table 3. ANOVA results based on figure 10.

\begin{tabular}{llllll}
\hline \hline Source & SS & df & MS & F & Prob $>$ F \\
\hline Columns & $3,53 \mathrm{E}+07$ & 3 & 11774070,7 & 19,91 & $9,98 \mathrm{E}-09$ \\
\hline Error & $3,07 \mathrm{E}+07$ & 52 & 591228,6 & & \\
\hline Total & $6,61 \mathrm{E}+07$ & 55 & & &
\end{tabular}




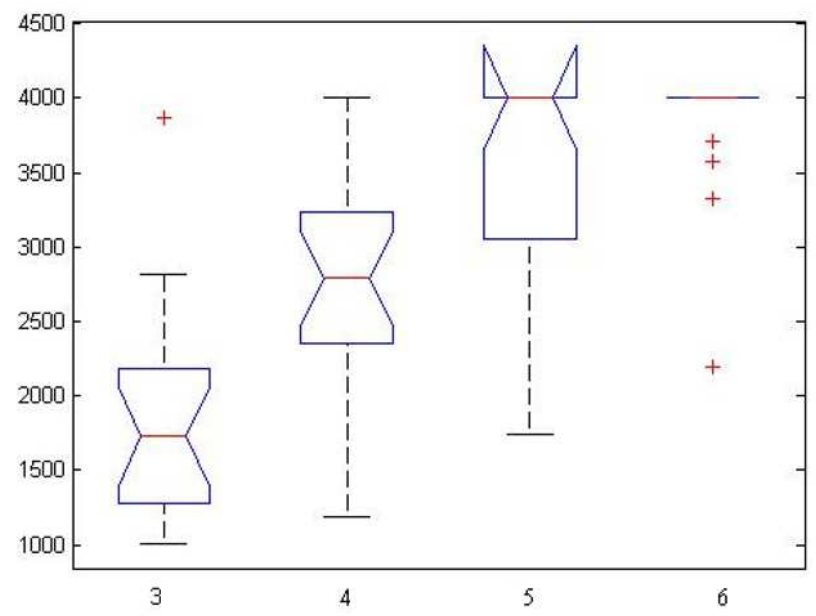

Figure 12. Boxplot of ANOVA based on figure 10 and table 4 (second experiment, 18 participants)

Table 4. ANOVA results based on figure 10.

\begin{tabular}{llllll}
\hline \hline Source & SS & df & MS & F & Prob $>$ F \\
\hline Columns & $4,30 \mathrm{E}+07$ & 3 & 14324064 & 30,1 & $1,69 \mathrm{E}-12$ \\
\hline Error & $3,24 \mathrm{E}+07$ & 68 & 475907,6 & & \\
\hline Total & $7,53 \mathrm{E}+07$ & 71 & & &
\end{tabular}

In order to compare the worst and best environmental conditions it is worth having a look at the first two runs (naive users' first attempts) and runs 5-6 (trained users with the application active). 


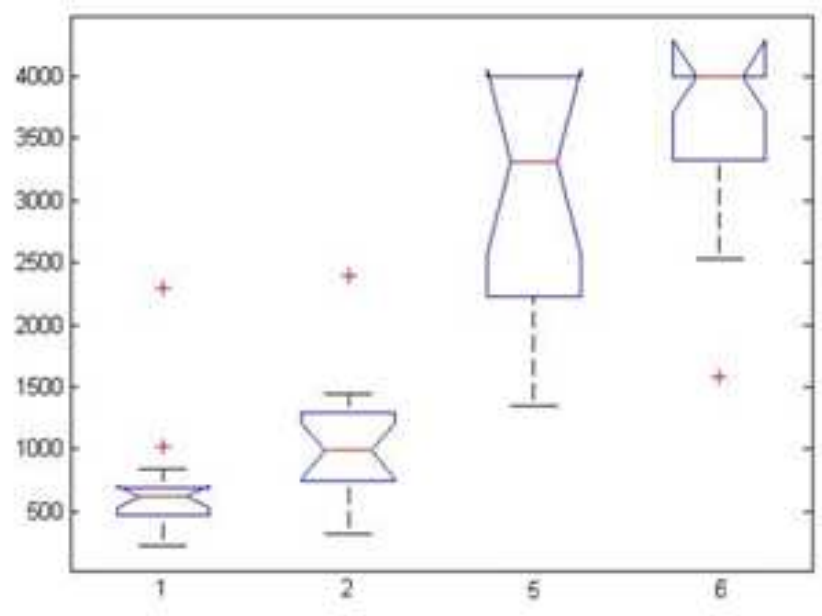

Figure 13. Boxplot of ANOVA based on the first runs without app and with the last two runs with application active (first experiment, 14 participants, table 5).

Table 5. ANOVA results based on figure 13.

\begin{tabular}{llllll}
\hline \hline Source & SS & df & MS & F & Prob $>$ F \\
\hline Columns & $8,51 \mathrm{E}+07$ & 3 & 28364058,9 & 58,7 & $1,04 \mathrm{E}-16$ \\
\hline Error & $2,51 \mathrm{E}+07$ & 52 & 483185,7 & & \\
\hline Total & $1,10 \mathrm{E}+08$ & 55 & & &
\end{tabular}

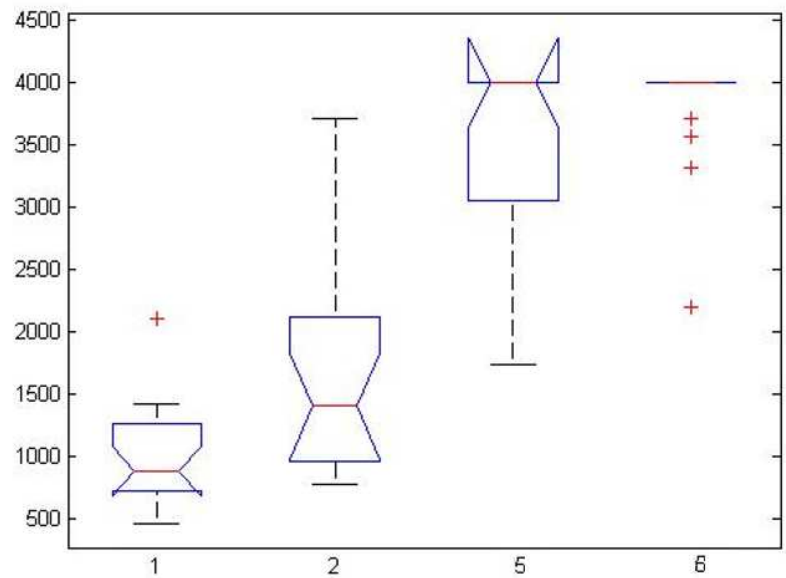


Figure 14. Boxplot of ANOVA based on the first runs without app and with the last two runs with application active (second experiment, 18 participants, table 6).

Table 6. ANOVA results based on figure 14.

\begin{tabular}{llllll}
\hline \hline Source & SS & df & MS & F & Prob $>$ F \\
\hline Columns & $1,06 \mathrm{E}+08$ & 3 & 35499218,2 & 97,67 & $1,34 \mathrm{E}-24$ \\
\hline Error & $2,47 \mathrm{E}+07$ & 68 & 363450,3 & & \\
\hline Total & $1,31 \mathrm{E}+08$ & 71 & & &
\end{tabular}

\section{Discussion}

The evaluation of results focused on the following parameters: effects of training (improvement in results without the application after training with the app), effects of fixing portability mode (handheld vs. belt) and contrasting best and worst-case scenarios.

Figures 6-9 show an effect of training. In both setups, independent of the portability mode, significant improvement can be seen between the first runs and the last runs. This is also supported by the ANOVA test (very low p-value).

Former tests indicated that the most important problem would be that of holding the device properly in the hand. First, it is unlikely that blind users having a white cane in one hand would use their other hand to hold a phone for the whole duration of their outdoor navigation. Second, unwanted movements of the wrist - both to the left and right, or turns of the upper body can mislead the user into disorientation. The direction of the device must therefore be consistent with the posture of the body, arm and walking direction at all times.

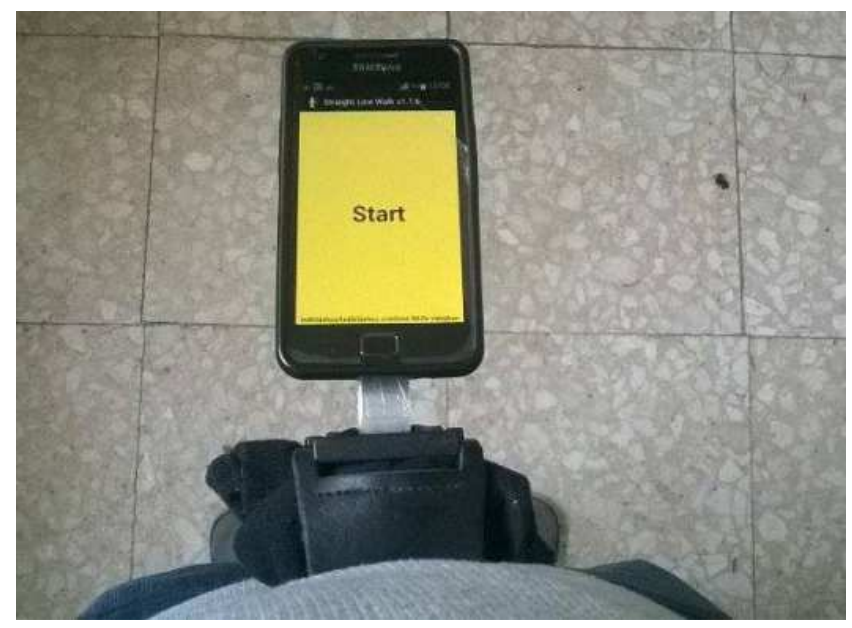


Figure 15. The device applied on a belt.

In order to avoid the problem mentioned above, a small tool was developed to hold the device on a belt around the hip, independent of arm and wrist movement. Figures 10-12 show the difference between results using the app. Altogether, four runs were completed with the handheld and belt-fixed device. ANOVA analysis showed a significant difference and improvement of the results in case of the belt-fixed version.

We were also interested in a comparison between the best and worst-case scenarios. During the first two runs, participants were naïve subjects and tried to walk blindfolded in straight line for the first time. On the other hand, during runs 5 and 6 , subjects were using the application for the third and fourth time, thus they were trained and were also familiar with the testing process. As expected, contrasting these two situations revealed the largest difference in the results, especially in the belt-fixed case.

In terms of the functionality of the app, it was concluded that it reduces, but does not completely eliminate veering. Subjects still veer in one direction from time to time. Further, after the app commands the subjects to correct their direction, they usually cross over the initial straight line, prompting the app to alert them that they are veering off from the path once again. Such effects depend strongly on the walking speed: the faster the user walks, the larger the amplitude of the veering. This can result in the user reaching the border line earlier than in the case of slower walking. Although we did not measure and determine an optimal walking speed, normal walking speeds are recommended during usage.

The first run, in which the device was held in the hand was performed by 6 blind users as well. Surprisingly, their results tended to be worse than those of sighted participants, perhaps due to the unfamiliar procedure and feeling of insecurity experienced during the tests.

To summarize: results of mean walking distances were better while using the belt instead of holding the device in the hand. However, the degree of improvement (i.e. improvement of the walking distance obtained by contrasting the first and last attempts) was higher in cases when the handheld device was used. The reason for this was simply that the use of the belt yielded better results from the start (first attempt) and thus, a smaller improvement was measured at the end. With the belt, more participants could complete the whole 40-meter distance. Altogether, the total number of participants was still relatively low. A more rigorous statistical analysis would require 25-30 subjects in each group. Such investigations are left for future work.

\section{Summary}

Blindfolded sighted subjects participated in a navigation test using a mobile application that reduces veering from a straight line during walking in outdoor environments, without the use of external auditory beacon signals. The application runs on a smartphone based on the Android platform, using data from the built-in magnetic sensor. The desired direction can be set in a one-degree accuracy, and the actual sensor 
data is averaged over 5 seconds. The application commands the user to head to the left or right in case of veering. Unsigned absolute values in meters were recorded from the starting point to the point where subjects left the marked straight line by more than 0.75 $\mathrm{m}$. Statistical analysis showed significant improvements in avoiding veering with the device, both when the device was held in the hand and worn on a belt around the hip. As expected, using a fixed belt position increased the accuracy of control and reduced inconsistencies between walking direction and body postures during movement. Furthermore, improvement in the task without the application was significant even after a short training time using the application (four runs).

\section{Acknowledgement}

This project has received funding from the European Union's Horizon 2020 research and innovation programme under grant agreement No 643636 "Sound of Vision".

\section{References}

[1] O. Balan, A. Moldoveanu, F. Moldoveanu: Navigational audio games - an effective approach towards improving spatial contextual learning for blind people, International Journal on Disability and Human Development, Vol. 14, No. 2, pp. 109-118, 2015

[2] M. Bujacz, P. Skulimowski, P. Strumillo: Naviton-A Prototype Mobility Aid for Auditory Presentation of Three-Dimensional Scenes to the Visually Impaired, J. of Audio Eng. Soc., Vol. 60, No. 9, pp. 696-708, 2012

[3] N. Bourbakis: Sensing Surrounding 3-D Space for Navigation of the Blind, IEEE Eng. Med. Biol. Mag., Vol. 27, No. 1, pp. 49-55, 2008

[4] L. Kay: Electronic aids for blind persons: an interdisciplinary subject, IEEE Proceedings on Physical Science, Measurement and Instrumentation, Management and Education - Reviews, Vol. 131, No. 7, pp. 559-576, 1984

[5] J. Wilson, B. N. Walker, J. Lindsay, C. Cambias, F. Dellaert: SWAN: System for Wearable Audio Navigation, in Proceedings of the 11th International Symposium on Wearable Computers (ISWC 2007), USA, 8 pages, 2007

[6] W. W. Gaver: Auditory Icons: using sound in computer interfaces, HumanComputer Interactions, Vol. 2, No. 2, pp. 167-177, 1986

[7] H. Petrie, S. Morley: The use of non-speech sounds in non-visual interfaces to the MS Windows GUI for blind computer users, in Proc. of the International Conference on Auditory Display, pp. 1-5, 1998

[8] M. Jeon, B. M. Walker: Spindex (Speech Index) Improves Auditory Menu Acceptance and Navigation Performance, ACM Transactions on Accessible Computing, Vol. 3, No. 3, Art.No. 10, 2011

[9] B. N. Walker, A. Nance, J. Lindsay: Spearcons: Speech-based earcons improve navigation performance in auditory menus, in Proc. of the International Conference on Auditory Display, pp. 63-68, 2006

[10]E. Fuchs, G. Flügge: Adult Neuroplasticity: More Than 40 Years of Research, Neural Plasticity, Vol. 2014, Article ID 541870, 10 pages, 2014 
[11] Gy. Wersényi, J. Répás: The Influence of Acoustic Stimuli on "Walking Straight" Navigation by Blindfolded Human Subjects, Acta Technica Jaurinensis, Vol. 5, No. 1, pp. 3-18, 2012

[12] Gy. Wersényi: Auditory Representations of a Graphical User Interface for a Better Human-Computer Interaction," in S. Ystad et al. (Eds.): Auditory Display. CMMR/ICAD 2009 post proceedings edition, Lecture Notes in Computer Science (LNCS) 5954, Springer Verlag, Berlin, pp. 80-102, 2010

[13]D. Guth, R. LaDuke: The veering tendency of blind pedestrians: An analysis of the problem and literature review, J. Vis. Impair. Blind., Vol. 88, No. 5, pp. 391-400, 1994

[14]Á. Csapó, Gy. Wersényi: Overview of auditory representations in human-machine interfaces, Journal ACM Computing Surveys (CSUR), Vol. 46, No. 2, Art.No. 19, 2013

[15]Á. Csapó, Gy. Wersényi, H. Nagy, T. Stockman: Survey of assistive technologies and applications for blind users on mobile platforms - a review and foundation for research, J. on Multimodal User Interfaces, Vol. 9, No.4, pp. 275-286, 2015

[16] http://www.brainpickings.org/index.php/2011/01/10/npr-why-cant-we-walkstraight/ - accessed 2016 January

[17] http://www.thenakedscientists.com/HTML/content/latest-questions/question/2900/ - accessed 2016 January

[18] https://www.youtube.com/watch? $\mathrm{v}=\mathrm{dYcvLw} \mathrm{jkkk}$ - accessed 2016 January

[19] C. Mohr, A. Lievesley: Test-retest stability of an experimental measure of human turning behaviour in right-handers, mixed-handers, and left-handers, Laterality, Vol. 12, No. 2, pp. 172-190, 2007

[20]A. Cheung, S. Zhang, C. Stricker, M. Srinivasan: Animal navigation: The difficulty of moving in a straight line, Biol. Cybern., Vol. 97, No. 1, pp. 47-61, 2007

[21] A.A. Schaeffer: Spiral movement in man, J. Morph. Physiol., Vol. 45, pp. 293-398, 1928

[22]H. S. Bracha, D. J. Seitz, J. Otemaa, S. D. Glick: Rotational movement (circling) in normal humans: Sex difference and relationship to hand, foot and eye preference, Brain Research. Vol. 411, No. 2, pp. 231-235, 1987

[23] C. Mohr, P. Brugger, H.S. Bracha, T. Landis, I. Viaud-Delmon: Human side preferences in three different whole-body movement tasks, Behav. Brain Res., Vol. 151, No. 1-2, pp. 321-326, 2004

[24]F. O. Guldberg: Die Cirkularbewegung als thierische Grundbewegung, ihre Ursache, Phänomenalität und Bedeutung, Z. Biol. , Vol. 35, pp. 419-458, 1897

[25]H. S. Bracha, D. J. Seitz, J. Otemaa, S. D. Glick: Rotational movement (circling) in normal humans: Sex difference and relationship to hand, foot and eye preference, Brain Research, Vol. 411, Vol. 2, pp. 231-235, 1987

[26] C. Mohr, P. Brugger, H. S. Bracha, T. Landis, I. Viaud-Delmon: Human side preferences in three different whole-body movement tasks, Behav. Brain Res., Vol. 151, No. 1-2, pp. 321-326, 2004

[27]B. Gurney: Leg length discrepancy, Gait \& Posture, Vol. 15, No. 2, pp. 195-206, 2002

[28] J. J. Rieser, D. H. Ashmead, C. R. Taylor, G. A. Youngquist: Visual perception and the guidance of locomotion without vision to previously seen targets, Perception, Vol. 19, No. 5, pp. 675-689, 1990 
[29] R. L. Klatzky, J. M. Loomis, R. G. Golledge, J. G. Cicinelli, S. Doherty, J. W. Pellegrino: Acquisition of route and survey knowledge in the absence of vision, $\mathrm{J}$. Mot. Behav., Vol. 22, No. 1, pp. 19-43, 1990

[30] J. L. Souman, I. Frissen, M. N. Sreenivasa, M. O. Ernst: Walking Straight into Circles, Current Biology, Vol. 19, No. 18, pp. 1538-1542, 2009

[31] T. Uetake: Can we really walk straight?, American Journal of Physical Anthropology, Vol. 89, No. 1., pp. 19-27, 1992

[32] J. W. Philbeck, J. M. Loomis, A. C. Beall: Visually perceived location is an invariant in the control of action, Perception \& Psychophysics, Vol. 59, No. 4, pp. $601-612,1997$

[33] Y. Takei, R. Grasso, A. Berthoz: Quantitative analysis of human walking trajectory on a circular path in darkness, Brain Research Bulletin, Vol. 40, No. 5-6, pp. 491495, 1996

[34] Y. Takei, R. Grasso, M.-A. Amorim, A. Berthoz: Circular trajectory formation during blind locomotion: a test for path integration and motor memory, Experimental Brain Research, Vol. 115, No. 2, pp. 361-368, 1997

[35] M. Schwartz: Haptic perception of the distance walked when blindfolded, Journal of Experimental Psychology: Human Perception and Performance, Vol. 25, No. 3, pp. 852-865, 1999

[36] https://play.google.com/store/apps/details?id=com.johnny.straightlinewalk.app 